\title{
Fronto-parietal Network Segregation Predicts Maintained Cognition in the Cognitively Healthy Oldest-old (85+): evidence for dedifferentiation
}

Sims SA ${ }^{1}$, Faulkner ME ${ }^{1}$, Stewart, $\mathrm{P}^{1}$, Merritt $\mathrm{S}^{2}$, Rezaei $\mathrm{RF}^{3}$, Bharadwaj $\mathrm{PK}^{4}$, Franchetti $\mathrm{MK}^{4}$, Raichlen DA ${ }^{5}$, Jessup $\mathrm{CJ}^{4}$, Hishaw $\mathrm{GA}^{4}$, Van Etten $\mathrm{EJ}^{4}$, Trouard $\mathrm{TP}^{4}$, Geldmacher $\mathrm{D}^{1}$, Wadley $\mathrm{VG}^{1}$, Alperin $\mathrm{N}^{2}$, Porges $\mathrm{EC}^{3}$, Woods $\mathrm{AJ}^{3}$, Cohen $\mathrm{RA}^{3}$, Levin $\mathrm{BE}^{2}$, Rundek $\mathrm{T}^{2}$, Alexander $\mathrm{GE}^{4}$, Visscher $\mathrm{KM}^{1}$

${ }^{1}$ University of Alabama at Birmingham School of Medicine and Evelyn F. McKnight Brain Institute, Birmingham, AL; ${ }^{2}$ University of Miami Miller School of Medicine and Evelyn F. McKnight Brain Institute, Miami, FL; ${ }^{3}$ University of Florida and Evelyn F. and William L. McKnight Brain Institute, Gainesville, FL; ${ }^{4}$ University of Arizona and Evelyn F. McKnight Brain Institute, Tucson, AZ; ${ }^{5}$ University of Southern California, Los Angeles, CA

Corresponding Author: Sara A Sims, snolin@uab.edu

\begin{abstract}
$\underline{\text { Abstract }}$
The understanding of brain network interactions in cognitively healthy older adults informs how brain characteristics vary as individuals age and how these variations affect cognitive functioning. A functional connectivity analysis can reveal important insight into the brain's organization, which is crucial to examining cognitive aging. We investigated functional network properties in 146 cognitively healthy participants aged 85+ in the McKnight Brain Aging Registry. We found that the segregation of the cortical association system and the segregation of the fronto-parietal network (FPN) were stronger predictors of cognition and executive function. Compared to other network metrics, the segregation of networks may be more closely linked with cognitive performance and age-related dedifferentiation. We also provide a healthy oldest-old $(85+)$ cortical parcellation that can be used in future work in this age group. This study shows that network segregation of the oldest-old brain supports cognition. Specifically, the FPN plays an important role in supporting overall cognition and executive function in an aging population. By studying network dynamics and cognitive abilities of healthy brain aging, we advance the literature on dedifferentiation in the oldest-old.
\end{abstract}

Keywords: oldest-old, cognitive aging, networks, segregation, FPN, CON, DMN, dedifferentiation 


\section{Introduction}

A critical societal goal is to slow or stop age-related cognitive decline - essentially, to develop strategies to make all oldest-old adults more like the rarer cognitively healthy oldest-old adults. Understanding the factors contributing to optimal cognitive function in aging individuals is essential to developing effective cognitive rehabilitation interventions. To better understand successful cognitive aging, we examined the healthy aging brain's network segregation in an elderly population. A large body of previous work has explored the aging brain's anatomical, physiological, and functional aspects. Here, we want to extend this work into an even older age group that is of particular interest due to their enduring cognition into late life.

Some cognitive domains are particularly susceptible to decline with age, such as memory and executive functions (e.g., complex attention, verbal fluency, and decision making) (Reuter-Lorenz, Festini, \& Jantz, 2016; Spaan, 2015). Deficits in memory and executive functions, in particular, are consistently found to be the strongest predictors of impaired functional ability in older adults (Martyr, Nelis, \& Clare, 2014; Tomaszewski Farias et al., 2009; Woods, Weinborn, Velnoweth, Rooney, \& Bucks, 2012). Impaired cognition can also be accompanied by problems in instrumental activities of daily living (IADLs) (Cahn-Weiner, Boyle, \& Malloy, 2002; Martyr et al., 2014; Tomaszewski Farias et al., 2009). Since executive functioning and memory are some of the earliest and most impactful losses of cognition with aging, it is important to understand what makes intact functioning in these domains possible in an aging population.

Executive functioning is a broad collection of cognitive capacities centered on command and control thinking and processing of information (Salthouse, 2005). Executive function encompasses sustained attention, updating, inhibition, switching, planning, working memory, set-shifting, and fluency (Fisk \& Sharp, 2004; Lamar, Zonderman, \& Resnick, 2002; McCabe, Roediger, McDaniel, Balota, \& Hambrick, 2010; Rabinovici, Stephens, \& Possin, 2015; Sorel \& Pennequin, 2008). Executive functioning is also essential for efficient use of many other cognitive skills such as memory (Duff, Schoenberg, Scott, \& Adams, 2005; Salthouse, Atkinson, \& Berish, 2003; Spaan, 2015), working memory (Miyake, Friedman, Rettinger, Shah, \& Hegarty, 2001), processing speed (Albinet, Boucard, Bouquet, \& Audiffren, 2012; Baudouin, Clarys, Vanneste, \& Isingrini, 2009; Schretlen et al., 2000), and attention (McCabe et al., 2010). Because of the multidimensional nature of executive function, it is difficult to assess it consistently throughout the literature. However, there is a reliable lower performance in executive functioning in normal aging populations (Fisk \& Sharp, 2004; Harada, Natelson Love, \& Triebel, 2013; Reuter-Lorenz et al., 2016; Salthouse et al., 2003; Spaan, 2015). Longitudinal work has shown that executive functioning declines faster in older age ranges (Zaninotto, Batty, Allerhand, \& Deary, 2018). In the present study, we assessed many aspects of the executive functioning skill, including fluency, working memory, set-shifting, planning, inhibition, switching, complex attention, and visuospatial planning. Memory is another well-studied cognitive domain that encompasses multiple processes, namely the encoding, consolidation, and retrieval of information (Huo, Li, Wang, Zheng, \& Li, 2018; Zlotnik \& Vansintjan, 2019). Measures of memory performance in this study included verbal, narrative, visual, and recognition and discrimination of learned and novel stimuli.

Brain networks play a crucial role in aging, and as part of the aging process, older adults exhibit changes in brain structural and functional network integrity that impact network dynamics (Marstaller, Williams, Rich, Savage, \& Burianová, 2015). Because of their correlation to cognitive performance, brain network dynamics have emerged as a major avenue to study 
aging and cognitive decline (Andrews-Hanna et al., 2007; Antonenko \& Flöel, 2014; Chan, Park, Savalia, Petersen, \& Wig, 2014; Cohen \& D’Esposito, 2016; Ng, Lo, Lim, Chee, \& Zhou, 2016; Shine et al., 2016; Wen et al., 2011). Networks can be described in terms of their properties (Bullmore \& Sporns, 2009; Damoiseaux, 2017; van den Heuvel \& Hulshoff Pol, 2010). Network integration describes how much the network's regions interact and can be calculated as the mean connectivity of nodes within a given network (within network connectivity). The network participation coefficient describes the variety of connections of a given node. A low participation coefficient occurs when a node is more selectively connected to its network, and high participation occurs when a node is widely connected to other networks (Rubinov \& Sporns, 2010). Modularity describes how separable a system is into parts (Rubinov \& Sporns, 2010). Lastly, segregation describes the balance of within and between network connectivity. Very high segregation indicates very isolated networks, and very low segregation indicates the networks are no longer separable (Wig, 2017).

Higher-order cognitive networks in the Association System of particular interest are the fronto-parietal network (FPN), cingulo-opercular network (CON), and the default mode network (DMN). The FPN and CON are both associated with executive functioning (Cohen, Gallen, Jacobs, Lee, \& D’Esposito, 2014; Dosenbach, Fair, Cohen, Schlaggar, \& Petersen, 2008; Gratton, Sun, \& Petersen, 2018; Hearne, Cocchi, Zalesky, \& Mattingley, 2017; Schmidt, Burge, Visscher, \& Ross, 2016; Yin, Deák, \& Chen, 2018), but address different aspects of this broad cognitive skill (Cohen et al., 2014; Dosenbach et al., 2008; Gratton et al., 2018; Hearne et al., 2017; Schmidt et al., 2016; Yin et al., 2018). The FPN is associated with complex attention and directing cognitive control (Avelar-Pereira, Bäckman, Wåhlin, Nyberg, \& Salami, 2017; Oschmann \& Gawryluk, 2020; Ray et al., 2019), while the CON is associated with sustained executive control and perceptual and attentional task maintenance (Coste \& Kleinschmidt, 2016; Hausman et al., 2020; Sadaghiani \& D'Esposito, 2015). DMN activation occurs during rest, internally focused tasks and memory processing, but is suppressed during cognitively demanding, externally focused tasks (Avelar-Pereira et al., 2017; Hampson, Driesen, Skudlarski, Gore, \& Constable, 2006; Hellyer et al., 2014; Ng et al., 2016; Sambataro et al., 2010; Sestieri, Corbetta, Romani, \& Shulman, 2011).

A neural system's functional specialization and segregation is determined by the network's balance of connections between and within the network and is indicative of organizational integrity (Chan, Alhazmi, Park, Savalia, \& Wig, 2017; Damoiseaux, 2017; Iordan et al., 2017; Koen, Srokova, \& Rugg, 2020; Varangis, Habeck, Razlighi, \& Stern, 2019). In older adults, functional networks have increased between-network connectivity and decreased within-network connectivity (Chan et al., 2017; Damoiseaux, 2017; Iordan et al., 2017; Koen et al., 2020; Varangis et al., 2019). Prior evidence has shown differing hypotheses for age-related cognitive decline, including the compensation hypothesis, the over-recruitment of brain regions within a network, and the dedifferentiation hypothesis, the loss of functional specialization and segregation in brain network activity, which has received greater support; however, these hypotheses are not mutually exclusive (Chan et al., 2014; Daselaar et al., 2015; Seider, Porges, Woods, \& Cohen, 2021; Siman-Tov et al., 2016). Previous studies have found that dedifferentiation of the FPN, CON, and DMN is associated with reduced performance in episodic memory, processing speed, attention, and executive function - all of which are vulnerable to the aging process (Chan et al., 2017; Damoiseaux, 2017; Goh, 2011; Hausman et al., 2020; Iordan et al., 2017; Koen et al., 2020; Nashiro, Sakaki, Braskie, \& Mather, 2017; Ng et al., 2016; Varangis et al., 2019). However, prior work on dedifferentiation has only been done in 
younger-old samples (largely 65-85 years old). Studying the younger-old can be confounded by including pre-symptomatic disease, since it is unknown which individuals may be experiencing undetectable, pre-clinical cognitive disorders or will continue to be cognitively healthy for another decade. The cognitively unimpaired oldest-old have lived into late ages, and we can be more confident in determining their status as successful agers. To the best of our knowledge, the relationship between the segregation of networks and overall cognition, including executive functioning and memory, in a healthy oldest old cohort has not been examined until now.

The purpose of this study is to understand the brain basis of preserved cognition in the context of functional network dynamics and, specifically, to understand how the FPN, CON, and DMN contribute to executive function and episodic memory. We expand on prior methods of studying functional networks and cognition by using an older, 85+ population and a brain parcellation made from our healthy oldest-old sample. Here we address the hypothesis that maintaining cognition into healthy aging relies on the segregation of the association system and its sub-networks: FPN, CON, and DMN. We used forward selection hierarchical regressions and canonical correlation between cognitive measures and network properties.

\section{$\underline{\text { 2. Results }}$}

We hypothesized that cognitive performance was related to the segregation of the Association System and its sub-networks: FPN, CON, and DMN. Therefore, we predicted that decreases in segregation within the Association System, FPN, CON, and DMN would be related to poorer overall cognition and poorer executive functioning and memory performance in oldest-old adults.

\subsection{A priori power analysis}

An a priori power analysis was conducted using a sample size of 146 in a canonical correlation, hierarchical multiple regression with one variable in block one and five variables in block two, and a hierarchical multiple regression with one variable in block one and ten variables in block two. Using the sample size of 146, all analyses can detect small effect sizes with an alpha of .05 and a power of .80. The smallest detectable effect for the canonical correlation was $\mathrm{r}=.23$, similar to the effect size found by Chan et al. (2014). The smallest detectable effect for hierarchical multiple regression with one variable in block one and five variables in block two was .092, and the hierarchical multiple regression with one variable in block one and ten variables in block two was .12.

\subsection{Exploratory Factor Analysis}

EFA revealed three factors: 1) Executive functioning: Sustained attention (EF-SA), 2) Episodic Memory, and 3) Executive functioning: Control (EF-C). (See Supplemental Table 1 for variable factor loadings). The episodic memory factor included the following measures: a word list learning task, the California Verbal Learning Test II (CVLT-II) long delay recall total score (Delis, Kramer, Kaplan, \& Ober, 1987); a story memory task, Craft Story paraphrase delayed recall total score (Beekly et al., 2007); and a visual memory task, Benson Figure Test recall score (Beekly et al., 2007). Executive functioning-sustained factor included a visual attention task, the Trail Making Test A-lines per second (Gaudino, Geisler, \& Squires, 1995); a category fluency task, Animal naming total correct score (Beekly et al., 2007); the number correct score from a speeded word reading test, Stroop Color-Word test (MacLeod, 1992); a verbal, processing speed test of decoding numbers and symbols, WAIS-IV Coding (Weschler, 2008); and a processing 
speed and visual perception task, WAIS-IV Symbol Search (Weschler, 2008). Executive functioning-control factor included a switching and inhibition task, the Stroop Color Word-Inhibition test interference score (MacLeod, 1992); WAIS-IV Letter-Number Sequencing longest correct sequence (Weschler, 2008); a working memory task, Digit Span Backward (Beekly et al., 2007); and a non-verbal reasoning task, WAIS-IV Matrix Reasoning (Weschler, 2008). The task switching task, Trail Making Test B lines per second (Gaudino et al., 1995), had a split loading between Executive functioning: Control/Switching and Executive functioning: Sustained attention. Since this task requires processing speed and switching, this split between the two factors is consistent with the task demands.

The EFA for the overall cognition factor had loadings from all variables and accounted for $30 \%$ of the variance. The highest loadings on the factor were Coding, Symbol Search, Trails A\&B, CVLT II long delay recall, and Matrix Reasoning. See supplemental materials for the EFA factor loadings that were constrained to 1 factor (Supplemental Table 2).

\subsection{Functional Connectivity of Network Nodes}

Using the ROIs we created (Figure 7), we generated a group average of Fisher's z-transformed correlation matrix grouped by network and system membership (Figure 1).

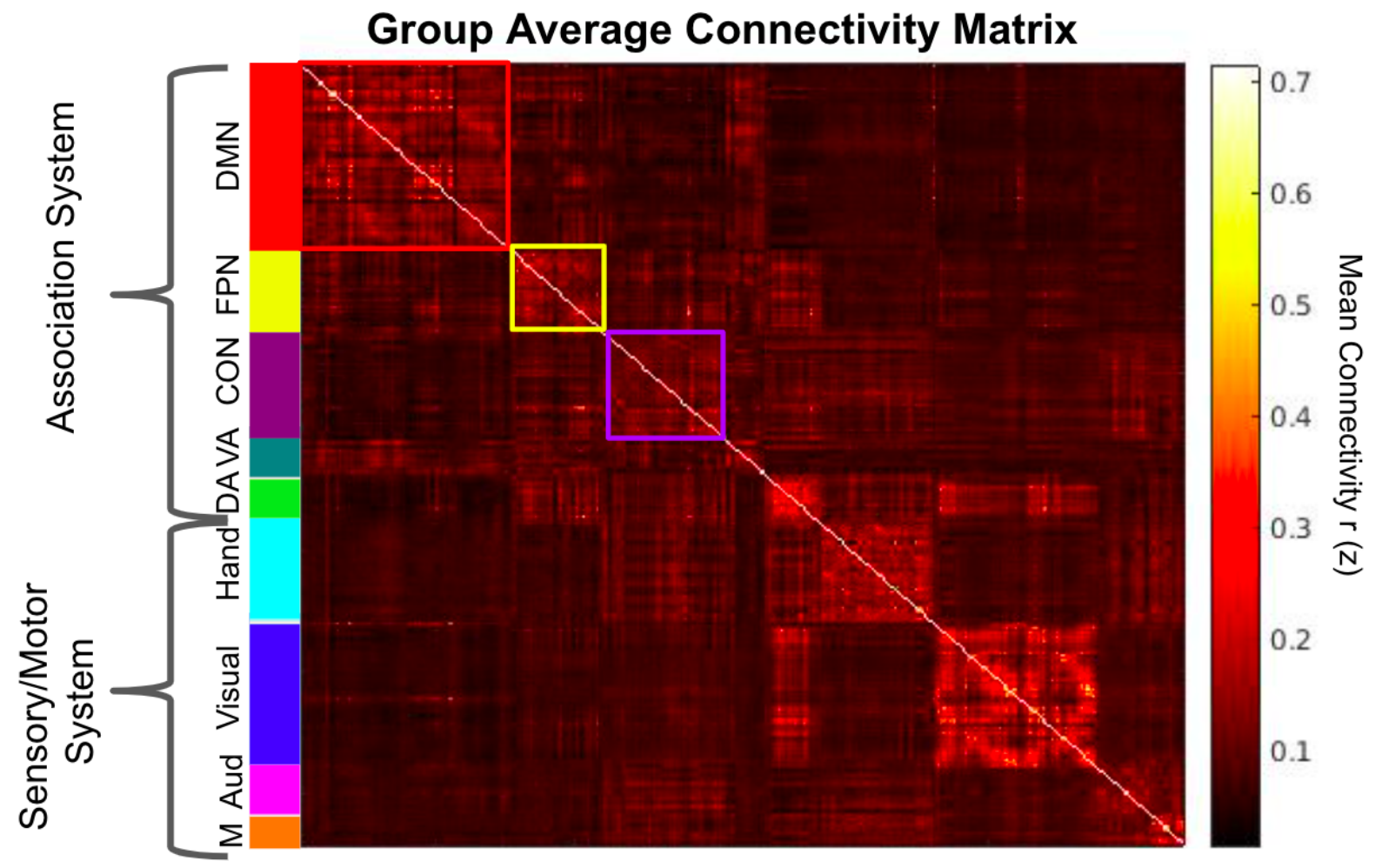

Figure 1. Group average Fisher's z- transformed correlation matrix of 321 nodes. The Association system consists of the Default mode (red), Fronto-parietal control (yellow), Ventral attention (teal), Cingulo-opercular control (purple), and Dorsal attention (green). The Sensory-Motor system consists of the Hand somato-motor (light blue), Visual (blue), Mouth somato-motor (orange), and Auditory networks (pink). 


\subsection{Association System metrics \& Overall Cognition}

\begin{tabular}{|c|c|c|c|}
\hline Table 1. Association System and Overall Cognition Metrics & Mean & SD & Range \\
\hline Segregation & 0.4205 & 0.1071 & $0.0929-0.6463$ \\
\hline Mean Within-Network Connectivity & 0.0833 & 0.0246 & $0.0162-0.1522$ \\
\hline Participation Coefficient & 0.4356 & 0.0235 & $0.3675-0.4746$ \\
\hline Modularity & 0.2561 & 0.0374 & $0.1321-0.3501$ \\
\hline Overall Cognition Factor Score & 0.0382 & 0.9295 & $-2.6497-2.329$ \\
\hline
\end{tabular}

We then generated descriptive statistics of association system metrics and the overall cognition metric (Table 1). Overall cognition was related to all association system metrics segregation $(\mathrm{r}=.343, \mathrm{p}<.001)$, participation coefficient $(\mathrm{r}=-.166, \mathrm{p}=.046)$, modularity $(\mathrm{r}=.249$, $\mathrm{p}=.003)$, and mean within-network connectivity $(\mathrm{r}=.173, \mathrm{p}=.037)$ (Figure 3$)$. However, Bonferroni corrected alpha for four comparisons was $\mathrm{p}<.0125$, and only Segregation and Modularity meet this criterion. Association system segregation was not correlated with the memory factor score, which had been previously found in work by Chan and colleagues (2017) (Figure 3). 

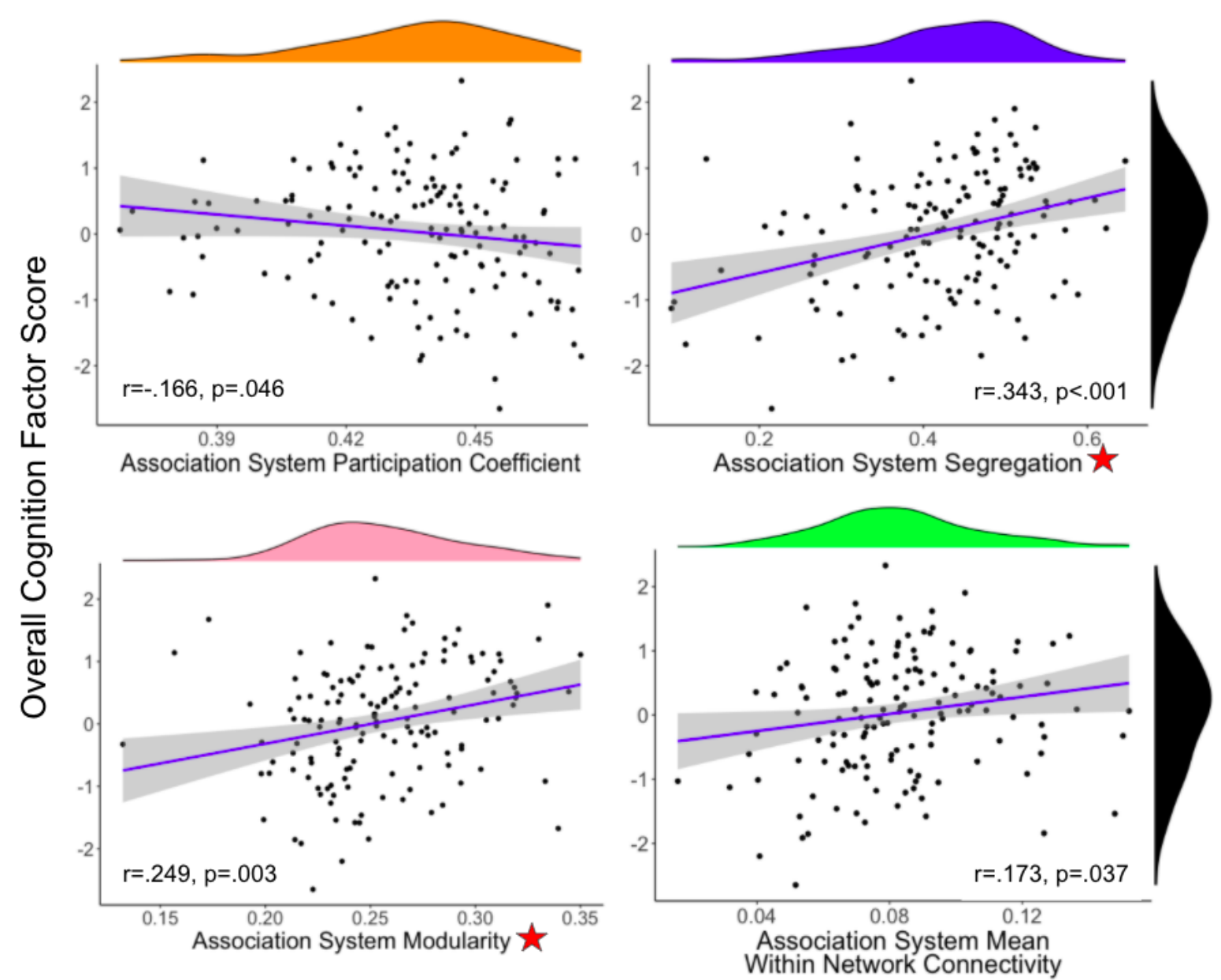

Figure 2. Scatter plots between Association System metrics and overall cognitive performance. Histograms for the variables are presented for each variable on the edge of the scatter plot. Each unique color of the density plots represents each variable consistently across figures: overall cognition score (black), association system participation coefficient (orange), association system segregation (blue), association system modularity (pink), and association system mean within-network connectivity (green). Bonferroni corrected alpha for four comparisons is .0125; only Segregation and Modularity meet this criterion (represented by a red star). 


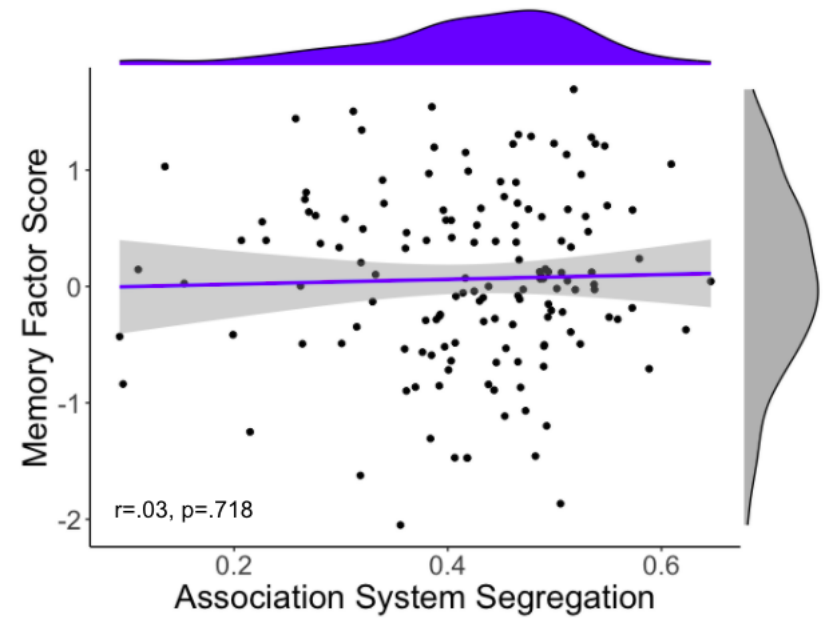

Figure 3. Scatterplot of Association System Segregation and Memory relationship ( $\mathrm{r}=.03, \mathrm{p}=.718$ ). Histograms for the variables are presented for each variable on the edge of the scatter plot. Grey represents memory factor score, and blue represents association system segregation. Association system segregation was not correlated with the memory factor score, which was previously found in Chan and colleagues' work (2017).

The forward selection hierarchical regression of overall cognition showed that segregation was the best predictor of overall cognition among the association system metrics. There was a significant $\mathrm{R}^{2}$-change of $.112(\mathrm{p}<.001)$ between the first block of the covariate, site, and the second block with association system segregation. The model accounted for $16.2 \%$ of the variance of overall cognition.

\subsection{Network metrics and Overall Cognition}

\begin{tabular}{|c|c|c|c|}
\hline$\underline{\text { Table 2. Network Metrics }}$ & Mean & SD & Range \\
\hline \multicolumn{4}{|l|}{ Segregation } \\
\hline DMN & 0.4517 & 0.1495 & $0.0628-0.7209$ \\
\hline FPN & 0.3279 & 0.1385 & $-0.0482-0.5989$ \\
\hline $\mathrm{CON}$ & 0.2784 & 0.1848 & $-0.2677-0.7439$ \\
\hline \multicolumn{4}{|l|}{ Participation Coefficient } \\
\hline $\mathrm{DMN}$ & 0.7631 & 0.0398 & $0.6293-0.8364$ \\
\hline FPN & 0.8199 & 0.0156 & $0.7782-0.8508$ \\
\hline $\mathrm{CON}$ & 0.8354 & 0.008 & $0.8062-0.8509$ \\
\hline \multicolumn{4}{|c|}{ Mean Within-Network Connectivity } \\
\hline DMN & 0.0156 & 0.0118 & $0.0005-0.0692$ \\
\hline FPN & 0.0882 & 0.0369 & $0.0181-0.2452$ \\
\hline $\mathrm{CON}$ & 0.0865 & 0.0378 & $0.0044-0.2229$ \\
\hline
\end{tabular}

We then investigated the relationship of overall cognition with the network metrics (participation coefficient, segregation, and mean connectivity) of 3 networks that belong to the Association System: FPN, CON, and DMN (Table 2). 
The forward selection hierarchical regression of overall cognition showed that FPN segregation was the best predictor of overall cognition among the network metrics. There was a significant $\mathrm{R}^{2}$-change of $.119(\mathrm{p}<.001)$ between the first block of the covariate, site, and the second block with FPN segregation. The model accounted for $16.3 \%$ of the variance of overall cognition.

To further describe specific relationships between overall cognition and network metrics, partial correlations with the site as a covariate are shown in Figure 4. Of note, Bonferroni corrected alpha for four comparisons was $\mathrm{p}<.005$, and only segregation for FPN and DMN met this criterion (partial correlation results can be found in Figure 4).
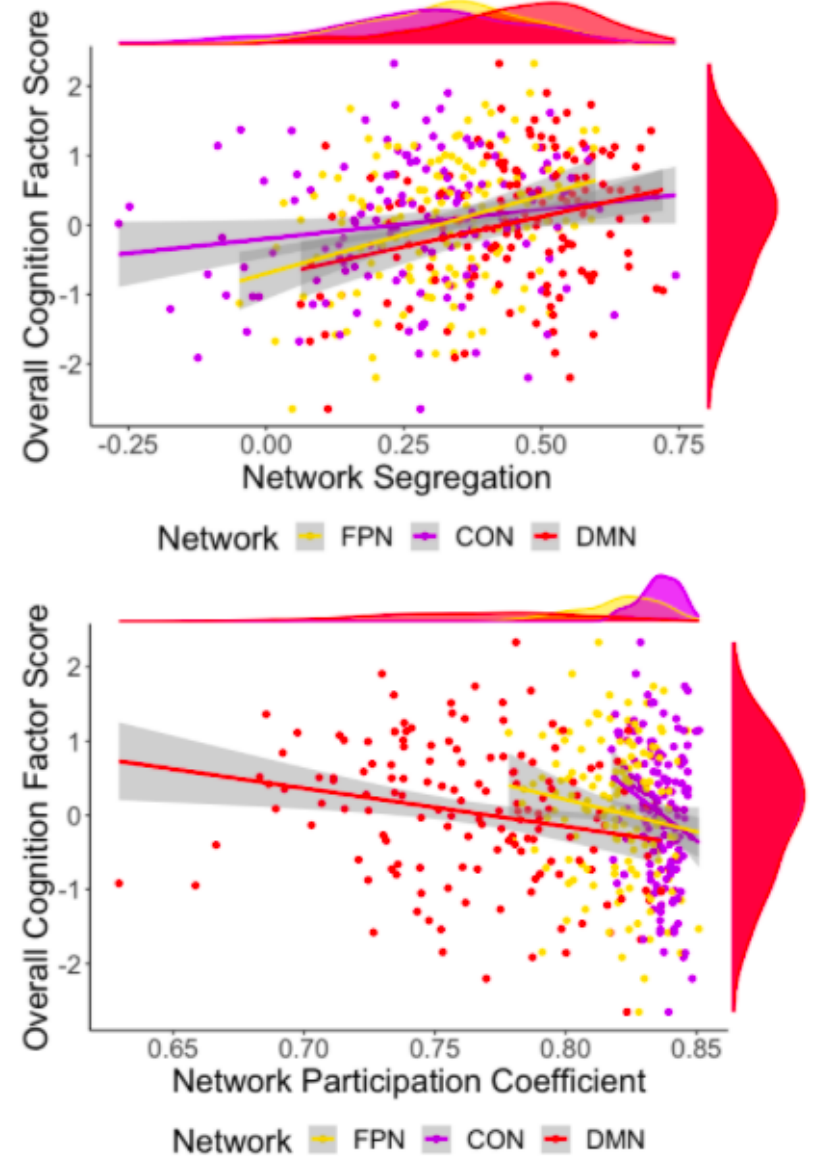

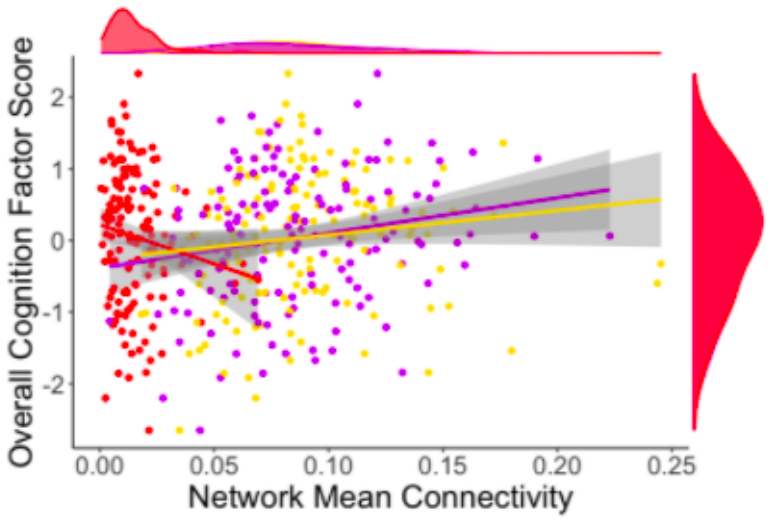

Network $\mathrm{FPN}=\mathrm{CON}=\mathrm{DMN}$

\begin{tabular}{|l|c|c|c|}
\hline & FPN & CON & DMN \\
\hline Segregation & $\begin{array}{l}\mathrm{r}=.365 \\
\mathrm{p}<.001\end{array}$ & $\begin{array}{c}\mathrm{r}=.177 \\
\mathrm{p}=.033\end{array}$ & $\begin{array}{l}\mathrm{r}=.275 \\
\mathbf{p}<.001\end{array}$ \\
\hline $\begin{array}{l}\text { Mean } \\
\text { Connectivity }\end{array}$ & $\begin{array}{l}\mathrm{r}=.111 \\
\mathrm{p}=.185\end{array}$ & $\begin{array}{l}\mathrm{r}=.214 \\
\mathrm{p}=.010\end{array}$ & $\begin{array}{l}\mathrm{r}=-.136 \\
\mathrm{p}=.103\end{array}$ \\
\hline $\begin{array}{l}\text { Participation } \\
\text { Coefficient }\end{array}$ & $\begin{array}{l}\mathrm{r}=-.130 \\
\mathrm{p}=.119\end{array}$ & $\begin{array}{l}\mathrm{r}=-.213 \\
\mathrm{p}=.010\end{array}$ & $\begin{array}{l}\mathrm{r}=-.216 \\
\mathrm{p}=.009\end{array}$ \\
\hline
\end{tabular}

Figure 4. Scatter plot of Overall Cognition and FPN (vellow). CON (purple), and DMN (red) network segregation. mean connectivity, and participation coefficient. Histograms for the variables are presented for each variable on the edge of the scatter plot. The colors on these plots match the network color in Figure 7. The table shows the corresponding partial correlation for each network and network metric to overall cognition; statistically significant findings $(\mathrm{p}>.05)$ are bolded. Bonferroni corrected alpha for four comparisons is .005; only Segregation for FPN and DMN meet this criterion.

\subsection{Network metrics and cognitive domains}

To further break down overall cognition into cognitive domains, we investigated the relationship between the previously described network metrics of the FPN, CON, and DMN and three domains of cognition: Memory, Executive functioning- sustained attention (EF-SA), and Executive functioning- control (EF-C) (Table 3). 
Canonical correlation between network metrics and cognitive domains is illustrated in Figure 5 (Thompson, 1991). We found that executive functioning (contributions from EF-SA and EF-C) significantly correlated with network dynamics $(r=.41, p=.019)$. The model accounted for $27.7 \%$ of the variance in the observed variables. Furthermore, the two highest canonical loadings on the network metric canonical variable were FPN segregation and DMN segregation. Specifically, poorer executive functioning was related to higher participation coefficients (i.e., more widely connected networks) of all networks, higher DMN mean connectivity, lower FPN and CON mean connectivity, and lower segregation of all networks (Figure 5).

\begin{tabular}{|c|c|c|c|}
\hline Table 3. Cognitive Domain Factor Scores & Mean & SD & Range \\
\hline Memory & 0.0646 & 0.759 & $-2.0496-1.693$ \\
\hline Executive Function - Sustained Attention & 0.0315 & 0.9004 & $-2.6189-2.4631$ \\
\hline Executive Function - Control & -0.0447 & 0.7885 & $-2.2671-2.1412$ \\
\hline
\end{tabular}

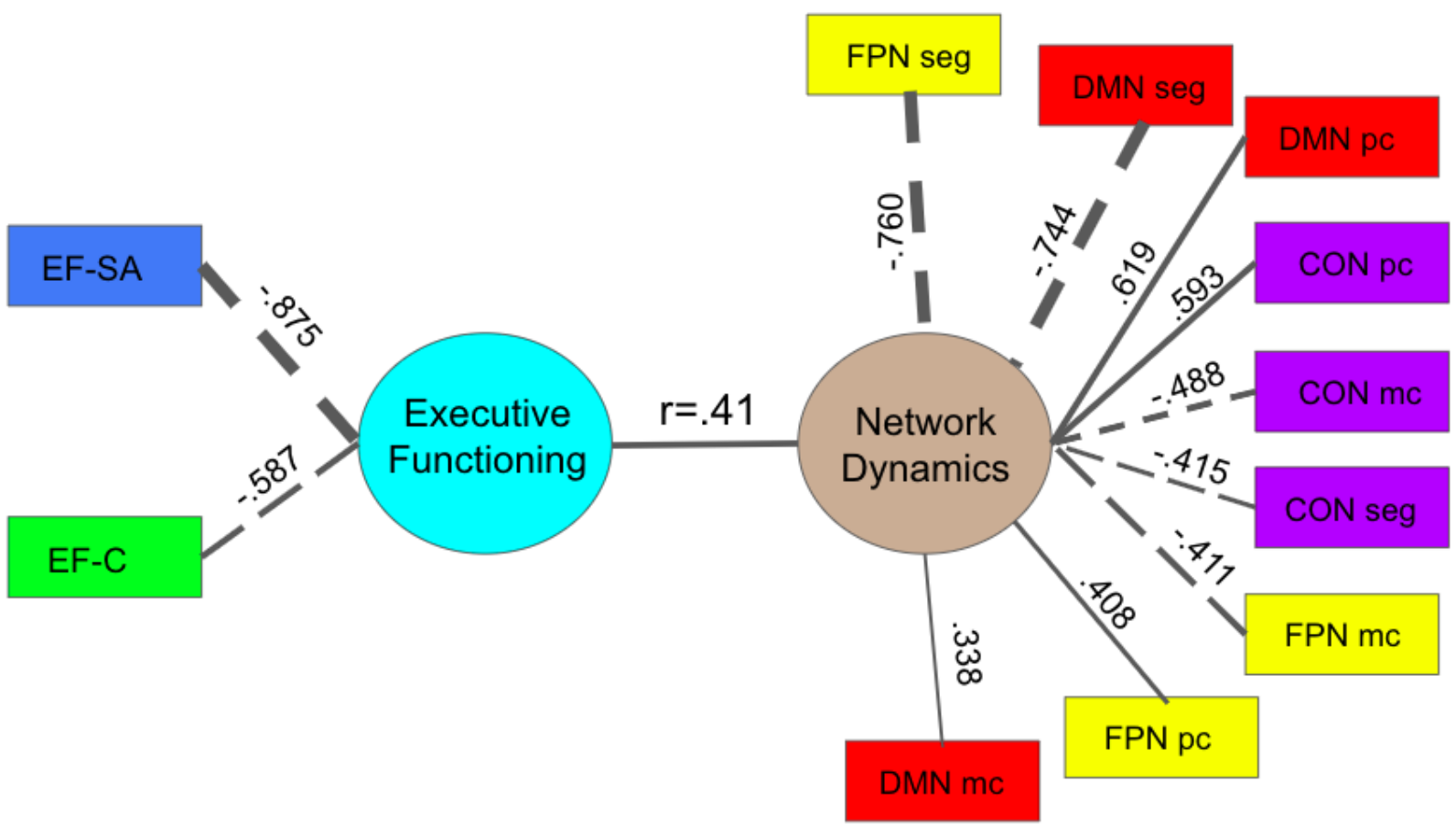

Figure 5. Canonical correlation model. Circles represent the canonical variables, and rectangles represent observed variables. The correlation coefficient between the two canonical variables is on the line between the two canonical variables $(\mathrm{r}=.41, \mathrm{p}<.001)$. The thickness of the lines represents the significance of the correlation between the canonical variables. Solid lines represent positive correlations, and dashed lines represent negative correlations. The value listed on the connections between the canonical variable and the observed variable is the loading for the observed variable on the canonical variable. "Seg" refers to segregation, "pc" refers to participation coefficient, and "mc" refers to mean connectivity.

To further describe specific relationships between cognitive domains and network metrics within the canonical correlation, relationships between the network metrics and the executive functioning canonical variable are shown in Figure 6. It is evident from these relationships that the distributions of these metrics for different networks vary in their relationship to executive 
bioRxiv preprint doi: https://doi.org/10.1101/2021.10.05.463207; this version posted October 7, 2021. The copyright holder for this preprint (which was not certified by peer review) is the author/funder, who has granted bioRxiv a license to display the preprint in perpetuity. It is made available under aCC-BY-NC-ND 4.0 International license.

function and the segregation of the DMN and FPN having a strong relationship with executive functioning.
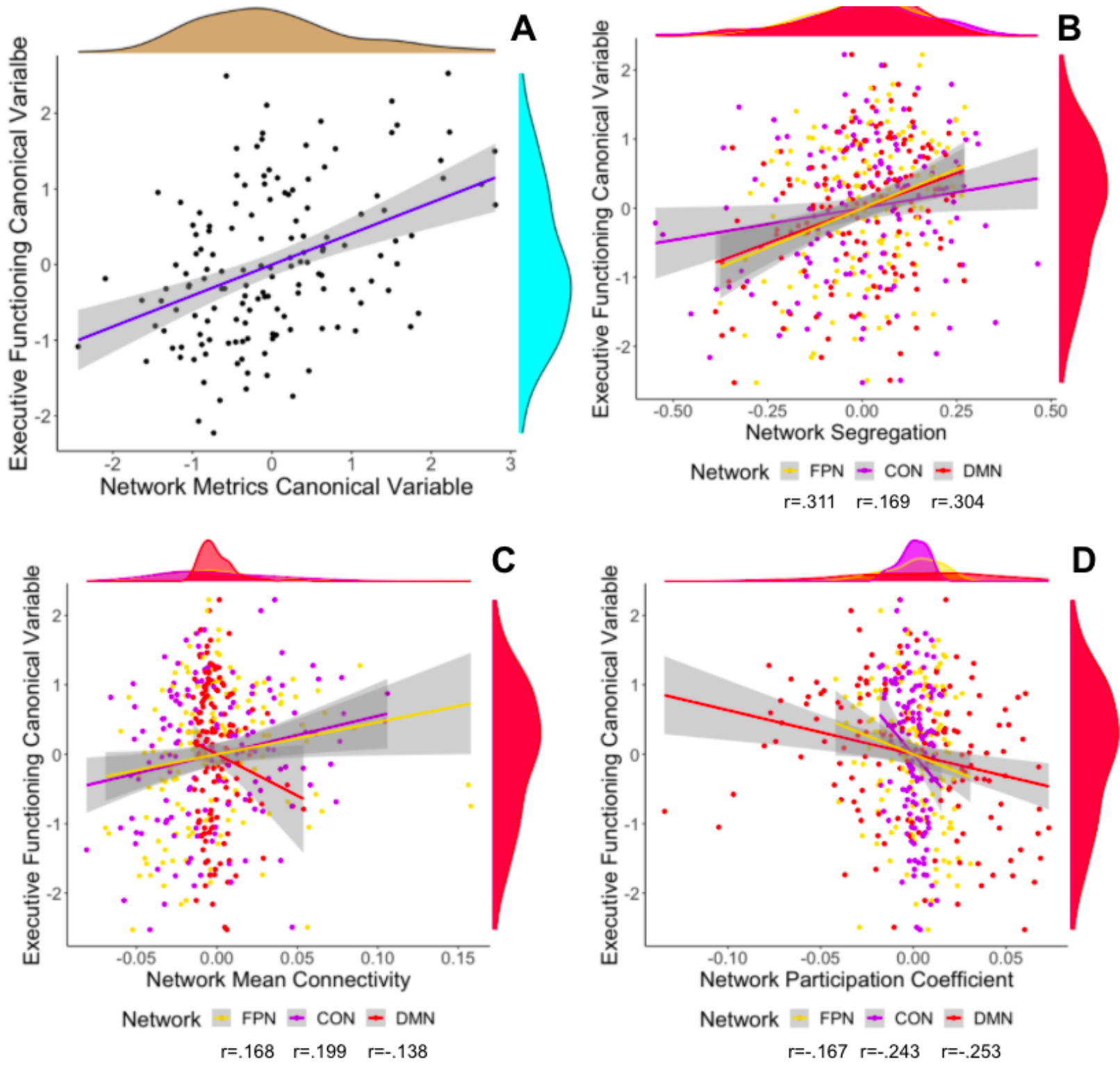

Figure 6. The top left shows the relationship between the canonical variables $(\mathrm{r}=.41, \mathrm{p}<.001)$. Brown represents network metrics, and light blue represents executive functioning in the same way as Figure 5 . The other three scatter plots show the relationship between the executive functioning canonical variable and the network metric for each network: FPN (yellow), CON (purple), and DMN (red). Histograms for the variables are presented for each variable on the edge of the scatter plot. The executive functioning canonical variable scores' sign was flipped to aid interpretability of the plots so that higher values indicate better executive functioning performance. 


\section{Discussion}

First, we created a set of parcels in oldest-old adults based on functional connectivity boundary-based mapping. We then showed that the segregation metric was the best predictor of cognitive functioning compared to other metrics of the association system. We then found that compared to metrics of the CON and DMN and other metrics of the FPN, the segregation of the FPN was the best predictor of overall cognition and executive functioning. Our findings indicated that the pattern of connectivity profiles across all networks (CON, DMN, and FPN), but especially FPN segregation, predicted executive functioning. This study demonstrates that the oldest-old brain is segregated within the association system and its networks, and that the FPN is important to supporting cognitive function and executive functioning especially as we age. Prior studies have largely examined younger older adults when studying network dynamics, thereby excluding an ever-growing portion of the older adult population. In this study, we expanded on prior methods of studying network functioning by using an older, $85+$ population to better understand how aspects of cognition are related to brain networks in the context of aging.

\subsection{Healthy Oldest-old network parcellation}

It is important to understand how a healthy aging cortex is subdivided, especially since brain network reorganization can change across the lifespan (Bagarinao et al., 2019). While boundary-based mapping and node identification has been applied to a sample that included individuals 85 and above (Chan et al., 2014; Han et al., 2018), with the sample from the McKnight Brain Aging Registry, we had the opportunity to apply the same methods to a sample with an older age range and larger sample size than previous work for the oldest-old portion of the sample. We provide a healthy oldest-old $(85+)$ parcellation that can be used in future work in this age group and can be used to compare to disease populations in this age range. It is important to have an age-appropriate parcellation because it can more accurately identify cortical mapping of networks. Future work will analyze the organization of the nodes in this parcellation and identify networks without younger-adult-based network descriptors.

\subsection{Age-related functional dedifferentiation}

Models of dedifferentiation and compensation are used to explain changes in the selectivity of functional activity of brain regions that occurs in the aging context (Koen et al., 2020; Li, Lindenberger, \& Sikström, 2001; Rakesh, Fernando, \& Mansour L, 2020; Reuter-Lorenz \& Cappell, 2008; Reuter-Lorenz, Stanczak, \& Miller, 1999). The neural dedifferentiation hypothesis posits that functional networks are not as selectively recruited (Goh, 2011; Koen et al., 2020). On the other hand, the compensation hypothesis posits that functional networks must recruit more regions or "over-activate" to complete the intended task (Reuter-Lorenz \& Cappell, 2008). These two models may be compatible (Burianová, Lee, Grady, $\&$ Moscovitch, 2013). The study of the association system and association networks across the lifespan has indicated that dedifferentiation is associated with age and a co-occurring decrease in cognitive functioning (Chan et al., 2014; Geerligs, Renken, Saliasi, Maurits, \& Lorist, 2015; Han et al., 2018). Longitudinal work on association system networks has indicated that segregation of association system networks decreases with age (Chong et al., 2019), and this rate of decline corresponds to declining cognitive functioning in the elderly (Malagurski, Liem, Oschwald, Mérillat, \& Jäncke, 2020; Ng et al., 2016). However, the mean age of participants in prior work was well below that of the current study. Therefore, it was unknown how far in the aging process dedifferentiation can continue while cognitive functions are maintained and to what degree different networks are sensitive to dedifferentiation in the oldest-old brain. 
The goal of this study was to further investigate cognition and brain network dedifferentiation in the context of successful brain aging in the oldest-old cohort by examining dedifferentiation through network metrics of segregation, participation coefficient, modularity, and within-network connectivity.

3.3 Dedifferentiation predicts preserved cognition in the cognitively healthy elderly

We found that association system segregation is a greater predictor of overall cognition than other widely-used measures of network integration and segregation. Additionally, only segregation and modularity were significantly correlated with overall cognition (Figure 2). The findings of our study support the dedifferentiation hypothesis, since the networks that compose the association system cannot function when they are not differentiated adequately. However, this finding does not exclude the compensation hypothesis; it is notable that the relationship between overall cognition and mean connectivity was rather weak $(r=.173, p=.037$, not significant after multiple comparison correction), which could indicate that individuals with better cognitive performance were not as likely to "over-activate" the networks.

When we analyzed specific networks within the association system, we found similar results to the overall association system; however, among the network properties of the FPN, $\mathrm{CON}$, and DMN, the network segregation of the FPN was the greatest predictor of overall cognition (Figure 4). Additionally, only the FPN and DMN segregation were significantly correlated with overall cognition (Figure 4). Although canonical correlation revealed contributions from all network metrics to executive functioning performance, FPN segregation contributed the most (Figure $5 \& 6$ ). We have shown that FPN segregation is related to one of the key cognitive functions of aging - executive functioning (Figure 5).

Prior studies have shown that FPN properties relate to executive functioning task performance and that other network properties, like DMN segregation, also contribute to executive functioning abilities (Madden et al., 2010; Reineberg, Andrews-Hanna, Depue, Friedman, \& Banich, 2015; Rieck, Baracchini, Nichol, Abdi, \& Grady, 2021). Recent research indicates that the FPN regulates other brain networks to support executive function (Avelar-Pereira et al., 2017; Marstaller et al., 2015). The FPN and DMN interact less efficiently in older adults compared to younger adults; the networks are coupled during rest and across tasks in older adults, suggesting that aging causes the FPN to have more difficulty flexibly engaging and disengaging networks (Avelar-Pereira et al., 2017; Grady, Sarraf, Saverino, \& Campbell, 2016; Spreng \& Schacter, 2012). Age-related within-network structural changes and between-network functional dedifferentiation may disrupt the FPN's ability to control other networks, like the DMN (Avelar-Pereira et al., 2017; Geerligs et al., 2015; Grady et al., 2016; Marstaller et al., 2015; Romero-Garcia, Atienza, \& Cantero, 2014; Zhang et al., 2014). Because of the FPN's function as a control network, age-related disruptions in FPN connectivity may explain the initial and most noticeable decline in cognition, processing speed ( $\mathrm{Ng}$ et al., 2016; Oschmann \& Gawryluk, 2020; Rieck, Baracchini, \& Grady, 2021).

The findings from this work support prior research by demonstrating that while dedifferentiation may occur in aging populations, executive function can be maintained in old age as long as the FPN and DMN remain well segregated. Further, the negative relationship between executive functioning and DMN connectivity may reflect that individuals with better executive functioning did not need to compensate by over-recruiting the DMN. Therefore, sustainable healthy cognitive aging may be marked by maintaining segregated network organization and not increased compensation. Further research will need to investigate the mechanisms of maintenance of network organization in healthy agers. 
While segregation is not the only metric that can detect dedifferentiation, our findings indicate that it more reliably relates to cognitive abilities. With segregation's greater predictive ability, it may serve as a more sensitive metric than other network metrics when assessing cognitive decline in aging populations. Additionally, our work helps inform other research that has indicated that segregation may be a marker of potential cognitive resilience in Alzheimer's Disease (Ewers et al., 2021). Studies have shown that learning-induced plasticity through cognitive training and exercise could be an avenue for changing network dynamics to improve cognitive performance (Iordan et al., 2017; Voss et al., 2010). Future research could target network dynamics in the older adult population to preserve cognitive functioning.

\subsection{Limitations and Future Directions}

This study has several limitations. Since this work is based on data collected across multiple sites, the data collection site was used as a covariate in partial correlation analysis and entered in the first block of hierarchical regression analyses. However, we recognize that this may not completely address site differences, such as different test administrators, different populations, scanner inhomogeneities, etc. We performed post-collection data quality assessment methods, including visual inspection of MRI and cognitive data, strict fMRI preprocessing steps, visual inspection of all generated surfaces and motion parameters, and double data entry for all cognitive data.

We also recognize that the generalizability of our findings is limited due to the limited diversity of our sample that is mostly non-Hispanic, Caucasian, and highly educated. Future work should be focused on broadening the diversity of oldest-old samples.

Given the cross-sectional nature of this work, we have limited information about our participants' state of health and cognitive performance earlier in life or what their cognitive health will be later in life. Thus, we are not able to investigate whether an individual's current functioning is a decline from prior functioning or if they will go on to develop cognitive impairment. The current work is the best guess as to what a range of best outcomes in cognitively healthy brain functioning looks like. The scope of this work is focused on healthy oldest-old and not the developmental process of aging. Therefore, inferences from this study focus on what we can learn from individuals who survived to $85+$ and are cognitively healthy in their oldest-old years.

\subsection{Conclusions}

This work provides novel insight into the healthy oldest-old brain and intact cognition in the aging process. Our work suggests that the organization of networks is critical for efficiently functioning networks that preserve cognitive abilities. We also provide evidence for the dedifferentiation hypothesis of aging. We show that cognition can be maintained when networks are more separable and can therefore be more selectively recruited. Specifically, the FPN may need the segregated organization of networks in order to play a central role in efficiently manipulating other networks for cognitive performance. We also show that better cognition in aging does not necessarily mean more compensation, since increased connectivity was relatively weakly or negatively correlated with better cognitive performance. This study advances the literature on the influence of network dynamics on cognitive ability in healthy brain aging. 


\subsection{Participants}

\section{Materials and Methods}

Data were collected as part of the McKnight Brain Aging Registry (MBAR), funded by the Evelyn F. McKnight Brain Foundation. Data were collected from the four McKnight Institutes: the University of Alabama at Birmingham, the University of Florida, the University of Miami, and the University of Arizona. The study sample includes 197 individuals with cognitive data and 146 with cognitive and MRI data, after excluding ten participants due to high head movement in MRI, six due to anatomical incompatibility with Freesurfer surface rendering, and one due to outlier network segregation values. Participants were aged 85 and older, screened for memory disorders, neurological disorders, and psychiatric disorders. Participants were recruited through mailings, flyers, physician referrals, and community-based recruitment. Participant characteristics are shown in Table 4. Participant characteristics of the full sample of 197 participants used in the cognitive data analysis can be found in supplemental Table 1 broken down by data collection site.

\begin{tabular}{|c|c|}
\hline Table 4. Participant Characteristics & Total Sample, $N=146$ \\
\hline Age (years), mean $\pm S D$ (range) & $88.4 \pm 3.18(85-99)$ \\
\hline Education (years), mean $\pm S D$ (range) & $16.1 \pm 3.03(9-26)$ \\
\hline \multicolumn{2}{|l|}{$\operatorname{Sex}, N(\%)$} \\
\hline Female & $79(54.11 \%)$ \\
\hline Male & $67(45.89 \%)$ \\
\hline \multicolumn{2}{|l|}{ Race, $N(\%)$} \\
\hline Non-Hispanic Caucasian & $134(91.78 \%)$ \\
\hline African American & $6(4.11 \%)$ \\
\hline Caucasian & $5(3.42 \%)$ \\
\hline Asian & $1(0.69 \%)$ \\
\hline \multicolumn{2}{|l|}{ Marital Status, $N(\%)$} \\
\hline Widowed & $74(50.69 \%)$ \\
\hline Married & $54(36.99 \%)$ \\
\hline Divorced & $13(8.90 \%)$ \\
\hline Living as Married/Domestic Partnership & $3(2.06 \%)$ \\
\hline Never Married & $2(1.37 \%)$ \\
\hline \multicolumn{2}{|l|}{ Dominant Hand, $N(\%)$} \\
\hline Right & $131(89.73 \%)$ \\
\hline Left & $15(10.27 \%)$ \\
\hline
\end{tabular}

\subsection{Cognitive Measures}

Multiple imputation is a statistical technique to estimate missing values in a dataset (Murray, 2018; Nassiri, Lovik, Molenberghs, \& Verbeke, 2018). In our multiple imputation 
analysis, all variables used in the subsequent exploratory factor analysis (EFA) were used in multiple imputations to address missingness in Stroop interference score (10 missing values), Trails B score ( 3 missing values), and Stroop word trial score (6 missing values). Missingness was due to administrator error, participant's inability to correctly perceive the stimuli due to low visual acuity or color blindness, or the participant not finishing a task in the allotted time. We obtained a similar mean and range of the variables when the dataset was restricted to only complete cases. Imputed data from 5 iterations were then pooled by the average of the imputed value across iterations.

An exploratory factor analysis (EFA) with varimax rotation was performed on 12 variables to identify cognitive domains. The EFA used all available cognitive data $(n=197)$. The number of factors was determined by eigenvalue greater than 1, analysis of scree plot, and parallel analysis, which indicated three factors (Humphreys \& Montanelli Jr., 1975; O'Connor, 2000; Zwick \& Velicer, 1986). Factor scores were then calculated using the regression method (Thomson, 1939). Cognitive measures used for this EFA can be found in supplemental Table 2. An additional EFA that was constrained to 1 factor was calculated to reflect overall cognitive ability. Factor scores for this 1 factor were also calculated using the regression method. Cognitive measures used for the 1 factor EFA can be found in supplemental Table 3.

Quality control was performed on behavioral data through Redcap double data entry, wherein data are entered twice, and discrepancies are identified and corrected (Harris et al., 2019, 2009). Data were also visually inspected for errors.

\subsection{Network Analysis}

\subsubsection{Imaging Acquisition}

For all subjects, an anatomical scan was collected (T1-weighted; repetition time (TR) = $2530 \mathrm{~ms}$; echo time $(\mathrm{TE})=3.37 \mathrm{~ms}$; field of view [FOV (ap,fh,rl)] $=240$ X 256 X $176 \mathrm{~mm}$; slice gap $=, 0$; voxel size $=1.0 \times 1.0 \times 1.0 \mathrm{~mm}$; flip angle $\left.(\mathrm{FA})=7^{\circ}\right)$. After the anatomical scan, a resting-state functional scan was collected $(\mathrm{T} 2 *$-weighted, TE/TR 30/2400 ms; FOV $=140$ X 5 $\mathrm{X} 140 ; \mathrm{FA}=70^{\circ}$; voxel size $=3.0 \times 3.0 \times 3.0 \mathrm{~mm}$; interleaved order of acquisition). Before the functional scan, participants were instructed to try to be as still as possible, stay awake, keep their eyes open, and let their minds wander without thinking of anything in particular. A central fixation cross was presented during the scan, which participants were told they could choose to look at during the scan.

\subsubsection{Preprocessing}

Anatomical images were preprocessed through Freesurfer (version 6.0) to render cortical surfaces (Fischl, 2012). Generated surfaces were then visually inspected for errors.

Before functional connectivity analysis, data were preprocessed with rigorous quality control methods for motion censoring (Carp, 2013; Gratton et al., 2020; Power, Barnes, Snyder, Schlaggar, \& Petersen, 2012; Power, Schlaggar, \& Petersen, 2015; Siegel et al., 2014), implemented by XCPEngine (Ciric et al., 2018) and fMRIPrep (Esteban et al., 2019). Nuisance regressors included global signal, cerebral spinal fluid (CSF), white matter (WM), the six motion parameters, their temporal derivatives, and their first order and quadratic expansion. Censoring included a framewise displacement threshold of $0.5 \mathrm{~mm}$, a DVARS threshold of 5, a high pass filter of 0.01 , and a low pass filter of 0.08 . Spatial smoothing of $4 \mathrm{~mm}$ was applied.

\subsubsection{Network Nodes}

We build upon Chan et al. (2014) and Han et al. (2018) by creating nodes from our oldest-old sample. Since our sample of oldest-old adults was larger and included more fMRI data per participant than Han et al. (2018) or Chan et al. (2014), we generated nodes from our sample 
using the same methods. Han et al. (2018) showed that while functional connectivity boundary-based parcellation of the human cortex was generally consistent across the lifespan, the boundaries become less similar to the younger adult boundaries as cohorts get older. However, the relationship between increasing age and decreasing system segregation was still intact even with older adult nodes (Han et al., 2018). This difference between young and oldest-old adult parcellations led us to use the same methods of boundary-based parcellation as Han et al. (2018) (Figure 7, Part A), the method of detection of local minima ROIs as Chan et al. (2014) (Figure 7, Part B), and network membership identification from the parcellation by Power et al. (2011) (Figure 7, Part C) to assess system and network segregation.

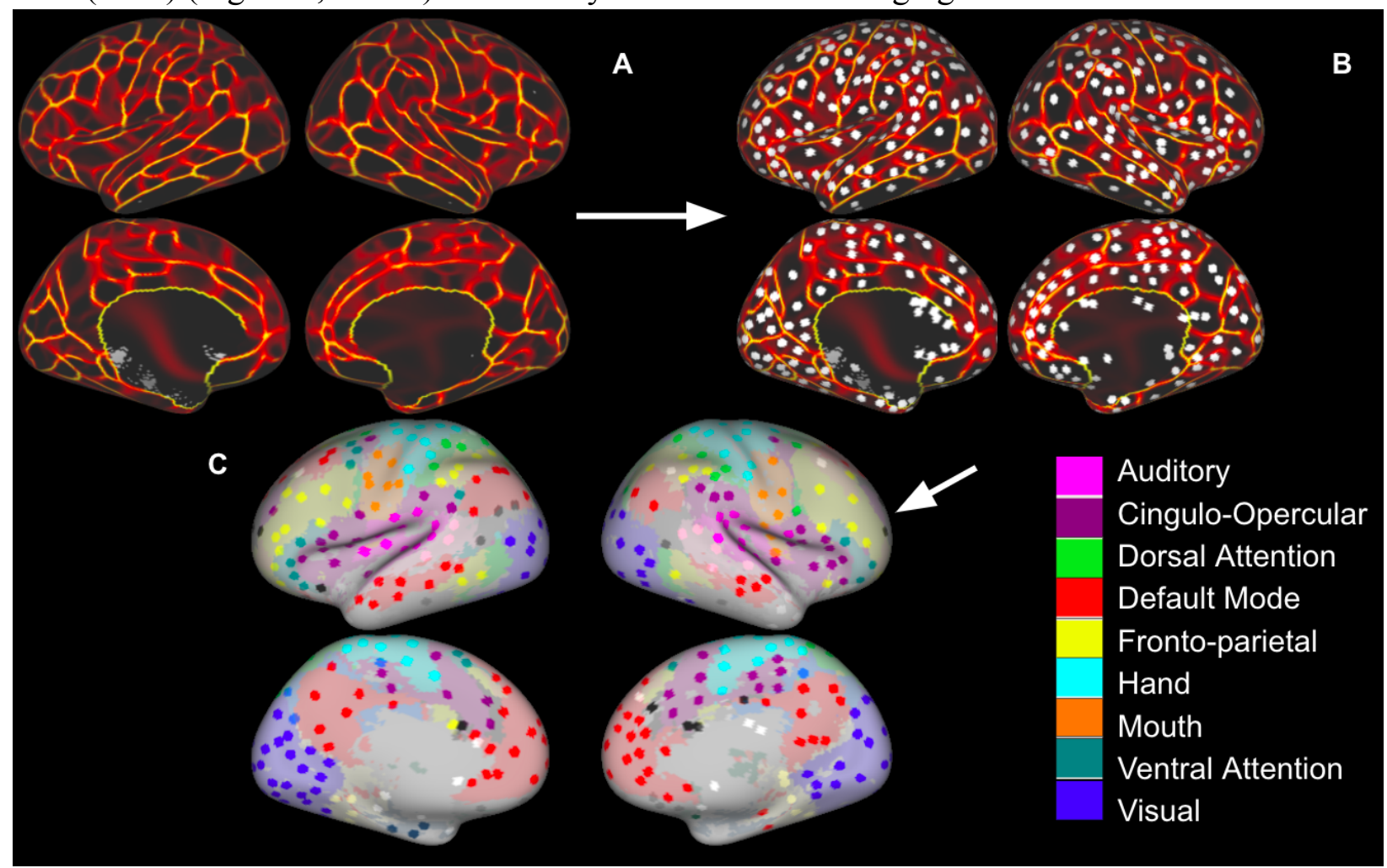

Figure 7. Regions of Interest Identification. A: Functional connectivity boundary maps based on methods used by (Han et al., 2018); B: Local minima ROIs based on methods used by (Chan et al., 2014); C: Local minima ROIs with the color of Network Membership of ROIs based on parcellation colors that are shown underneath ROIs (Power et al., 2011).

\subsubsection{Calculation of Network Properties}

In each participant, a mean time course was computed for each node from the atlas. A node-to-node correlation matrix was formed by correlating each node's time course with every node (Figure 1). The matrix of Pearson's $r$ values was then transformed into Fisher's z. Only positive correlations were retained for all metrics except the within-network mean connectivity for which both negative and positive values were incorporated. Within-network connectivity was calculated as the mean node-to-node z-value of all the nodes within that network. Segregation was calculated as within-network connectivity minus between-network connectivity, divided by within-network connectivity (Chan et al., 2014; Wig, 2017). Participation coefficient and modularity were calculated using the Brain Connectivity Toolbox (Rubinov \& Sporns, 2010). 


\subsubsection{Relating Cognition to Network metrics}

Two forward selection hierarchical regressions were performed to assess the predictors of overall cognition. For the first forward selection hierarchical regression, the data collection site was entered as the first block, and association system metrics were entered as the second block, including segregation, modularity, mean network connectivity, and participation coefficient. For the second forward selection hierarchical regression, the data collection site was entered as the first block, and metrics of the DMN, CON, and FPN were entered as the second block, including participation coefficient, mean network connectivity, and segregation. Partial correlations with the site as a covariate were assessed for variables within each regression, and Bonferroni correction was used for multiple comparison correction.

A canonical correlation was performed to assess the relationship between the set of cognitive domains (EF-SA, EF-C, and Memory) and the set of network metrics (participation coefficient, mean network connectivity, and segregation of the FPN, CON, and DMN) (Figure 5) (Thompson, 1991). Partial correlations with the site as a covariate were assessed for variables within the canonical correlation (Figure 6). 


\section{Acknowledgments}

Thank you to all those that helped with data collection and data management from the MBAR collaborative team. Thank you to all of the participants for volunteering their time and energy in contributing to this study. Thank you to UAB Research Computing and other members of the Visscher lab. Thank you for funding by the Evelyn F. McKnight Brain Foundation.

Data and code availability statement

Data is available through the Mcknight Brain Aging Registry.

Code is available at https://github.com/Visscher-Lab/FPN_segregation_paper 
bioRxiv preprint doi: https://doi.org/10.1101/2021.10.05.463207; this version posted October 7, 2021. The copyright holder for this preprint (which was not certified by peer review) is the author/funder, who has granted bioRxiv a license to display the preprint in perpetuity. It is made available under aCC-BY-NC-ND 4.0 International license.

\section{Supplemental Materials}

\begin{tabular}{|c|c|c|c|c|c|}
\hline$\frac{\text { Supplemental Table 1. Participant }}{\text { Characteristics }}$ & Total, $\mathrm{N}=146$ & $\begin{array}{c}\mathrm{UAB}^{1}, \mathrm{~N}=48 \\
(32.9 \%)\end{array}$ & $\begin{array}{c}\mathrm{UA}^{2}, \mathrm{~N}=35 \\
(24.0 \%)\end{array}$ & $\begin{array}{c}\mathrm{UF}^{3}, \mathrm{~N}=35 \\
(24.0 \%)\end{array}$ & $\begin{array}{l}\mathrm{UM}^{4}, \mathrm{~N}=28 \\
\quad(19.2 \%)\end{array}$ \\
\hline Age (years), mean $\pm S D$ (range) & $\begin{array}{l}88.4 \pm 3.18 \\
(85-99)\end{array}$ & $\begin{array}{l}88.4 \pm 3.47 \\
(85-98)\end{array}$ & $\begin{array}{l}88.7 \pm 2.98 \\
(85-95)\end{array}$ & $\begin{array}{l}89.1 \pm 3.65 \\
(85-99)\end{array}$ & $\begin{array}{l}87.1 \pm 1.70 \\
(85-91)\end{array}$ \\
\hline Education (years), mean $\pm S D$ (range) & $\begin{array}{l}16.1 \pm 3.03 \\
\quad(9-26)\end{array}$ & $\begin{array}{l}15.7 \pm 2.62 \\
(12-22)\end{array}$ & $15.9 \pm 2.89(9-22)$ & $\begin{array}{l}16.5 \pm 3.30 \\
(10-22)\end{array}$ & $\begin{array}{l}16.5 \pm 3.52 \\
(12-26)\end{array}$ \\
\hline \multicolumn{6}{|l|}{$\operatorname{Sex}, N(\%)$} \\
\hline Female & $79(54.11 \%)$ & $24(50.00 \%)$ & $18(51.43 \%)$ & $20(57.14 \%)$ & $17(60.71 \%)$ \\
\hline Male & $67(45.89 \%)$ & $24(50.00 \%)$ & $17(48.57 \%)$ & $15(42.86 \%)$ & $11(39.29 \%)$ \\
\hline \multicolumn{6}{|l|}{ Race, $N(\%)$} \\
\hline Non-Hispanic Caucasian & $134(91.78 \%)$ & $44(91.67 \%)$ & $33(94.29 \%)$ & $35(100.00 \%)$ & $22(78.57 \%)$ \\
\hline African American & $6(4.11 \%)$ & $4(8.33 \%)$ & $0(0.00 \%)$ & $0(0.00 \%)$ & $2(7.14 \%)$ \\
\hline Hispanic Caucasian & $5(3.42 \%)$ & $0(0.00 \%)$ & $2(5.71 \%)$ & $0(0.00 \%)$ & $3(10.71 \%)$ \\
\hline Asian & $1(0.69 \%)$ & $0(0.00 \%)$ & $0(0.00 \%)$ & $0(0.00 \%)$ & $1(3.57 \%)$ \\
\hline \multicolumn{6}{|l|}{ Marital Status, $N(\%)$} \\
\hline Widowed & $74(50.69 \%)$ & $27(56.25 \%)$ & $16(45.71 \%)$ & $19(54.29 \%)$ & $12(42.86 \%)$ \\
\hline Married & $54(36.99 \%)$ & $17(35.42 \%)$ & $12(34.29 \%)$ & $13(37.14 \%)$ & $12(42.86 \%)$ \\
\hline Divorced & $13(8.90 \%)$ & $4(8.33 \%)$ & $3(8.57 \%)$ & $3(8.57 \%)$ & $3(10.71 \%)$ \\
\hline $\begin{array}{c}\text { Living as Married/Domestic } \\
\text { Partnership }\end{array}$ & $3(2.06 \%)$ & $0(0.00 \%)$ & $3(8.57 \%)$ & $0(0.00 \%)$ & $0(0.00 \%)$ \\
\hline Never Married & $2(1.37 \%)$ & $0(0.00 \%)$ & $1(2.86 \%)$ & $0(0.00 \%)$ & $1(3.57 \%)$ \\
\hline \multicolumn{6}{|l|}{ Dominant Hand, $N(\%)$} \\
\hline Right & $131(89.73 \%)$ & $45(93.75 \%)$ & $29(82.86 \%)$ & $33(94.29 \%)$ & $24(85.71 \%)$ \\
\hline Left & $15(10.27 \%)$ & $3(6.25 \%)$ & $6(17.14 \%)$ & $2(5.71 \%)$ & $4(14.29 \%)$ \\
\hline
\end{tabular}

${ }^{1} \mathrm{UAB}$, University of Alabama at Birmingham; ${ }^{2} \mathrm{UA}$, University of Arizona; ${ }^{3} \mathrm{UF}$, University of Florida; ${ }^{4} \mathrm{UM}$, University of Miami 


\begin{tabular}{|c|c|c|c|}
\hline Supplemental Table 2. Factor Loadings for & EF-SA Factor & Memory Factor & EF-C Factor \\
\hline Cognitive Domains & 0.807 & & \\
\hline WAIS-IV Coding & -0.724 & & \\
\hline Trail Making Test A (lines/sec) & 0.667 & & \\
\hline Stroop Color-Word Reading Trial & 0.612 & & \\
\hline WAIS-IV Symbol Search & -0.508 & & -0.318 \\
\hline Trail Making Test B (lines/sec) & & 0.755 & \\
\hline CVLT II Long Delay Recall & & 0.574 & \\
\hline Craft Story Paraphrase Delay Recall & & 0.398 & \\
\hline Benson Figure Test Delay Recall & & & 0.59 \\
\hline Stroop Color Word-Inhibition Test & & & 0.514 \\
\hline Interference & & & 0.458 \\
\hline Digit Span Backward & & & 0.42 \\
\hline WAIS-IV Matrix Reasoning & & & \\
\hline WAIS-IV Letter-Number Sequencing & & & \\
\hline
\end{tabular}

\begin{tabular}{|c|c|}
\hline Supplemental Table 3. Overall Cognition & Factor 1 \\
\hline Factor Loadings & 0.749 \\
\hline WAIS-IV Coding & -0.649 \\
\hline Trail Making Test A (lines/sec) & 0.496 \\
\hline Stroop Color-Word Reading Trial & 0.714 \\
\hline WAIS-IV Symbol Search & -0.65 \\
\hline Trail Making Test B (lines/sec) & 0.458 \\
\hline CVLT II Long Delay Recall & 0.328 \\
\hline Craft Story Paraphrase Delay Recall & 0.214 \\
\hline Benson Figure Test Delay Recall & 0.182 \\
\hline Stroop Color Word-Inhibition Test \\
Interference & 0.357 \\
\hline Digit Span Backward & 0.453 \\
\hline WAIS-IV Matrix Reasoning & 0.272 \\
\hline WAIS-IV Letter-Number Sequencing &
\end{tabular}


Bibliography

Albinet, C. T., Boucard, G., Bouquet, C. A., \& Audiffren, M. (2012). Processing speed and executive functions in cognitive aging: how to disentangle their mutual relationship? Brain and Cognition, 79(1), 1-11. doi: 10.1016/j.bandc.2012.02.001

Andrews-Hanna, J. R., Snyder, A. Z., Vincent, J. L., Lustig, C., Head, D., Raichle, M. E., \& Buckner, R. L. (2007). Disruption of large-scale brain systems in advanced aging. Neuron, 56(5), 924-935. doi: 10.1016/j.neuron.2007.10.038

Antonenko, D., \& Flöel, A. (2014). Healthy aging by staying selectively connected: a mini-review. Gerontology, 60(1), 3-9. doi: 10.1159/000354376

Avelar-Pereira, B., Bäckman, L., Wåhlin, A., Nyberg, L., \& Salami, A. (2017). Age-Related Differences in Dynamic Interactions Among Default Mode, Frontoparietal Control, and Dorsal Attention Networks during Resting-State and Interference Resolution. Frontiers in Aging Neuroscience, 9, 152. doi: 10.3389/fnagi.2017.00152

Bagarinao, E., Watanabe, H., Maesawa, S., Mori, D., Hara, K., Kawabata, K., .. Sobue, G. (2019). Reorganization of brain networks and its association with general cognitive performance over the adult lifespan. Scientific Reports, 9(1), 11352. doi:

$10.1038 / \mathrm{s} 41598-019-47922-\mathrm{x}$

Baudouin, A., Clarys, D., Vanneste, S., \& Isingrini, M. (2009). Executive functioning and processing speed in age-related differences in memory: contribution of a coding task. Brain and Cognition, 71(3), 240-245. doi: 10.1016/j.bandc.2009.08.007

Beekly, D. L., Ramos, E. M., Lee, W. W., Deitrich, W. D., Jacka, M. E., Wu, J., ... NIA Alzheimer's Disease Centers. (2007). The National Alzheimer's Coordinating Center (NACC) database: the Uniform Data Set. Alzheimer Disease and Associated Disorders, 21(3), 249-258. doi: 10.1097/WAD.0b013e318142774e 
Bullmore, E., \& Sporns, O. (2009). Complex brain networks: Graph theoretical analysis of structural and functional systems. Nature Reviews. Neuroscience, 10(3), 186-198. doi: $10.1038 / \mathrm{nrn} 2575$

Burianová, H., Lee, Y., Grady, C. L., \& Moscovitch, M. (2013). Age-related dedifferentiation and compensatory changes in the functional network underlying face processing. Neurobiology of Aging, 34(12), 2759-2767. doi: 10.1016/j.neurobiolaging.2013.06.016

Cahn-Weiner, D. A., Boyle, P. A., \& Malloy, P. F. (2002). Tests of executive function predict instrumental activities of daily living in community-dwelling older individuals. Applied Neuropsychology, 9(3), 187-191. doi: 10.1207/S15324826AN0903_8

Carp, J. (2013). Optimizing the order of operations for movement scrubbing: Comment on Power et al. Neuroimage, 76, 436-438. doi: 10.1016/j.neuroimage.2011.12.061

Chan, M. Y., Alhazmi, F. H., Park, D. C., Savalia, N. K., \& Wig, G. S. (2017). Resting-State Network Topology Differentiates Task Signals across the Adult Life Span. The Journal of Neuroscience, 37(10), 2734-2745. doi: 10.1523/JNEUROSCI.2406-16.2017

Chan, M. Y., Park, D. C., Savalia, N. K., Petersen, S. E., \& Wig, G. S. (2014). Decreased segregation of brain systems across the healthy adult lifespan. Proceedings of the National Academy of Sciences of the United States of America, 111(46), E4997-5006. doi: $10.1073 /$ pnas. 1415122111

Chong, J. S. X., Ng, K. K., Tandi, J., Wang, C., Poh, J.-H., Lo, J. C., ... Zhou, J. H. (2019). Longitudinal changes in the cerebral cortex functional organization of healthy elderly. The Journal of Neuroscience, 39(28), 5534-5550. doi: 10.1523/JNEUROSCI.1451-18.2019

Ciric, R., Rosen, A. F. G., Erus, G., Cieslak, M., Adebimpe, A., Cook, P. A., ... Satterthwaite, T. D. (2018). Mitigating head motion artifact in functional connectivity MRI. Nature 
Protocols, 13(12), 2801-2826. doi: 10.1038/s41596-018-0065-y

Cohen, J. R., \& D’Esposito, M. (2016). The segregation and integration of distinct brain networks and their relationship to cognition. The Journal of Neuroscience, 36(48), 12083-12094. doi: 10.1523/JNEUROSCI.2965-15.2016

Cohen, J. R., Gallen, C. L., Jacobs, E. G., Lee, T. G., \& D’Esposito, M. (2014). Quantifying the reconfiguration of intrinsic networks during working memory. Plos One, 9(9), e106636. doi: 10.1371/journal.pone.0106636

Coste, C. P., \& Kleinschmidt, A. (2016). Cingulo-opercular network activity maintains alertness. Neuroimage, 128, 264-272. doi: 10.1016/j.neuroimage.2016.01.026

Damoiseaux, J. S. (2017). Effects of aging on functional and structural brain connectivity. Neuroimage, 160, 32-40. doi: 10.1016/j.neuroimage.2017.01.077

Daselaar, S. M., Iyengar, V., Davis, S. W., Eklund, K., Hayes, S. M., \& Cabeza, R. E. (2015). Less wiring, more firing: low-performing older adults compensate for impaired white matter with greater neural activity. Cerebral Cortex, 25(4), 983-990. doi: 10.1093/cercor/bht289

Delis, D. C., Kramer, J. H., Kaplan, E., \& Ober, B. A. (1987). California Verbal Learning Test (2nd ed.).

Dosenbach, N. U. F., Fair, D. A., Cohen, A. L., Schlaggar, B. L., \& Petersen, S. E. (2008). A dual-networks architecture of top-down control. Trends in Cognitive Sciences, 12(3), 99-105. doi: 10.1016/j.tics.2008.01.001

Duff, K., Schoenberg, M. R., Scott, J. G., \& Adams, R. L. (2005). The relationship between executive functioning and verbal and visual learning and memory. Archives of Clinical Neuropsychology, 20(1), 111-122. doi: 10.1016/j.acn.2004.03.003

Esteban, O., Markiewicz, C. J., Blair, R. W., Moodie, C. A., Isik, A. I., Erramuzpe, A., ... 
Gorgolewski, K. J. (2019). fMRIPrep: a robust preprocessing pipeline for functional MRI.

Nature Methods, 16(1), 111-116. doi: 10.1038/s41592-018-0235-4

Ewers, M., Luan, Y., Frontzkowski, L., Neitzel, J., Rubinski, A., Dichgans, M., ... Alzheimer's Disease Neuroimaging Initiative and the Dominantly Inherited Alzheimer Network. (2021). Segregation of functional networks is associated with cognitive resilience in Alzheimer's disease. Brain: A Journal of Neurology. doi: 10.1093/brain/awab112

Fischl, B. (2012). FreeSurfer. Neuroimage, 62(2), 774-781. doi: 10.1016/j.neuroimage.2012.01.021

Fisk, J. E., \& Sharp, C. A. (2004). Age-related impairment in executive functioning: updating, inhibition, shifting, and access. Journal of Clinical and Experimental Neuropsychology, 26(7), 874-890. doi: 10.1080/13803390490510680

Gaudino, E. A., Geisler, M. W., \& Squires, N. K. (1995). Construct validity in the Trail Making Test: what makes Part B harder? Journal of Clinical and Experimental Neuropsychology, 17(4), 529-535. doi: 10.1080/01688639508405143

Geerligs, L., Renken, R. J., Saliasi, E., Maurits, N. M., \& Lorist, M. M. (2015). A Brain-Wide Study of Age-Related Changes in Functional Connectivity. Cerebral Cortex, 25(7), 1987-1999. doi: 10.1093/cercor/bhu012

Goh, J. O. S. (2011). Functional Dedifferentiation and Altered Connectivity in Older Adults: Neural Accounts of Cognitive Aging. Aging and Disease, 2(1), 30-48.

Grady, C., Sarraf, S., Saverino, C., \& Campbell, K. (2016). Age differences in the functional interactions among the default, frontoparietal control, and dorsal attention networks. Neurobiology of Aging, 41, 159-172. doi: 10.1016/j.neurobiolaging.2016.02.020 Gratton, C., Dworetsky, A., Coalson, R. S., Adeyemo, B., Laumann, T. O., Wig, G. S., ... 
Campbell, M. C. (2020). Removal of high frequency contamination from motion estimates in single-band fMRI saves data without biasing functional connectivity. Neuroimage, 217, 116866. doi: 10.1016/j.neuroimage.2020.116866

Gratton, C., Sun, H., \& Petersen, S. E. (2018). Control networks and hubs. Psychophysiology, 55(3). doi: 10.1111/psyp.13032

Hampson, M., Driesen, N. R., Skudlarski, P., Gore, J. C., \& Constable, R. T. (2006). Brain connectivity related to working memory performance. The Journal of Neuroscience, 26(51), 13338-13343. doi: 10.1523/JNEUROSCI.3408-06.2006

Han, L., Savalia, N. K., Chan, M. Y., Agres, P. F., Nair, A. S., \& Wig, G. S. (2018). Functional parcellation of the cerebral cortex across the human adult lifespan. Cerebral Cortex, 28(12), 4403-4423. doi: 10.1093/cercor/bhy218

Harada, C. N., Natelson Love, M. C., \& Triebel, K. L. (2013). Normal cognitive aging. Clinics in Geriatric Medicine, 29(4), 737-752. doi: 10.1016/j.cger.2013.07.002

Harris, P. A., Taylor, R., Minor, B. L., Elliott, V., Fernandez, M., O’Neal, L., ... REDCap Consortium. (2019). The REDCap consortium: Building an international community of software platform partners. Journal of Biomedical Informatics, 95, 103208. doi: 10.1016/j.jbi.2019.103208

Harris, P. A., Taylor, R., Thielke, R., Payne, J., Gonzalez, N., \& Conde, J. G. (2009). Research electronic data capture (REDCap)--a metadata-driven methodology and workflow process for providing translational research informatics support. Journal of Biomedical Informatics, 42(2), 377-381. doi: 10.1016/j.jbi.2008.08.010

Hausman, H. K., O’Shea, A., Kraft, J. N., Boutzoukas, E. M., Evangelista, N. D., Van Etten, E. J., ... Woods, A. J. (2020). The Role of Resting-State Network Functional Connectivity in 
Cognitive Aging. Frontiers in Aging Neuroscience, 12, 177. doi: 10.3389/fnagi.2020.00177

Hearne, L. J., Cocchi, L., Zalesky, A., \& Mattingley, J. B. (2017). Reconfiguration of Brain Network Architectures between Resting-State and Complexity-Dependent Cognitive Reasoning. The Journal of Neuroscience, 37(35), 8399-8411. doi:

\subsection{3/JNEUROSCI.0485-17.2017}

Hellyer, P. J., Shanahan, M., Scott, G., Wise, R. J. S., Sharp, D. J., \& Leech, R. (2014). The control of global brain dynamics: opposing actions of frontoparietal control and default mode networks on attention. The Journal of Neuroscience, 34(2), 451-461. doi:

\subsection{3/JNEUROSCI.1853-13.2014}

Humphreys, L. G., \& Montanelli Jr., R. G. (1975). An investigation of the parallel analysis criterion for determining the number of common factors. Multivariate Behavioral Research, 10(2), 193-205. doi: 10.1207/s15327906mbr1002_5

Huo, L., Li, R., Wang, P., Zheng, Z., \& Li, J. (2018). The default mode network supports episodic memory in cognitively unimpaired elderly individuals: different contributions to immediate recall and delayed recall. Frontiers in Aging Neuroscience, 10, 6. doi: 10.3389/fnagi.2018.00006

Iordan, A. D., Cooke, K. A., Moored, K. D., Katz, B., Buschkuehl, M., Jaeggi, S. M., ... Reuter-Lorenz, P. A. (2017). Aging and Network Properties: Stability Over Time and Links with Learning during Working Memory Training. Frontiers in Aging Neuroscience, 9, 419. doi: 10.3389/fnagi.2017.00419

Koen, J. D., Srokova, S., \& Rugg, M. D. (2020). Age-related neural dedifferentiation and cognition. Current Opinion in Behavioral Sciences, 32, 7-14. doi: 10.1016/j.cobeha.2020.01.006 
Lamar, M., Zonderman, A. B., \& Resnick, S. (2002). Contribution of specific cognitive processes to executive functioning in an aging population. Neuropsychology, 16(2), 156-162. doi: 10.1037/0894-4105.16.2.156

Li, S. C., Lindenberger, U., \& Sikström, S. (2001). Aging cognition: from neuromodulation to representation. Trends in Cognitive Sciences, 5(11), 479-486. doi: 10.1016/s1364-6613(00)01769-1

MacLeod, C. M. (1992). The Stroop task: The "gold standard" of attentional measures. Journal of Experimental Psychology: General, 121(1), 12-14. doi: 10.1037/0096-3445.121.1.12

Madden, D. J., Costello, M. C., Dennis, N. A., Davis, S. W., Shepler, A. M., Spaniol, J., ... Cabeza, R. (2010). Adult age differences in functional connectivity during executive control. Neuroimage, 52(2), 643-657. doi: 10.1016/j.neuroimage.2010.04.249

Malagurski, B., Liem, F., Oschwald, J., Mérillat, S., \& Jäncke, L. (2020). Functional dedifferentiation of associative resting state networks in older adults - A longitudinal study. Neuroimage, 214, 116680. doi: 10.1016/j.neuroimage.2020.116680

Marstaller, L., Williams, M., Rich, A., Savage, G., \& Burianová, H. (2015). Aging and large-scale functional networks: white matter integrity, gray matter volume, and functional connectivity in the resting state. Neuroscience, 290, 369-378. doi: 10.1016/j.neuroscience.2015.01.049

Martyr, A., Nelis, S. M., \& Clare, L. (2014). Predictors of perceived functional ability in early-stage dementia: self-ratings, informant ratings and discrepancy scores. International Journal of Geriatric Psychiatry, 29(8), 852-862. doi: 10.1002/gps.4071

McCabe, D. P., Roediger, H. L., McDaniel, M. A., Balota, D. A., \& Hambrick, D. Z. (2010). The relationship between working memory capacity and executive functioning: evidence for a 
common executive attention construct. Neuropsychology, 24(2), 222-243. doi:

$10.1037 / \mathrm{a} 0017619$

Miyake, A., Friedman, N. P., Rettinger, D. A., Shah, P., \& Hegarty, M. (2001). How are visuospatial working memory, executive functioning, and spatial abilities related? A latent-variable analysis. Journal of Experimental Psychology: General, 130(4), 621-640. doi: 10.1037/0096-3445.130.4.621

Murray, J. S. (2018). Multiple imputation: A review of practical and theoretical findings. Statistical Science, 33(2), 142-159. doi: 10.1214/18-STS644

Nashiro, K., Sakaki, M., Braskie, M. N., \& Mather, M. (2017). Resting-state networks associated with cognitive processing show more age-related decline than those associated with emotional processing. Neurobiology of Aging, 54, 152-162. doi: 10.1016/j.neurobiolaging.2017.03.003

Nassiri, V., Lovik, A., Molenberghs, G., \& Verbeke, G. (2018). On using multiple imputation for exploratory factor analysis of incomplete data. Behavior Research Methods. doi: $10.3758 / \mathrm{s} 13428-017-1000-9$

Ng, K. K., Lo, J. C., Lim, J. K. W., Chee, M. W. L., \& Zhou, J. (2016). Reduced functional segregation between the default mode network and the executive control network in healthy older adults: A longitudinal study. Neuroimage, 133, 321-330. doi:

10.1016/j.neuroimage.2016.03.029

O’Connor, B. P. (2000). SPSS and SAS programs for determining the number of components using parallel analysis and velicer's MAP test. Behavior Research Methods, Instruments, \& Computers : A Journal of the Psychonomic Society, Inc, 32(3), 396-402. doi: 10.3758/bf03200807 
Oschmann, M., \& Gawryluk, J. R. (2020). A Longitudinal Study of Changes in Resting-State Functional Magnetic Resonance Imaging Functional Connectivity Networks During Healthy Aging. Brain Connectivity, 10(7), 377-384. doi: 10.1089/brain.2019.0724

Power, J. D., Barnes, K. A., Snyder, A. Z., Schlaggar, B. L., \& Petersen, S. E. (2012). Spurious but systematic correlations in functional connectivity MRI networks arise from subject motion. Neuroimage, 59(3), 2142-2154. doi: 10.1016/j.neuroimage.2011.10.018

Power, J. D., Cohen, A. L., Nelson, S. M., Wig, G. S., Barnes, K. A., Church, J. A., ... Petersen, S. E. (2011). Functional network organization of the human brain. Neuron, 72(4), 665-678. doi: 10.1016/j.neuron.2011.09.006

Power, J. D., Schlaggar, B. L., \& Petersen, S. E. (2015). Recent progress and outstanding issues in motion correction in resting state fMRI. Neuroimage, 105, 536-551. doi: 10.1016/j.neuroimage.2014.10.044

Rabinovici, G. D., Stephens, M. L., \& Possin, K. L. (2015). Executive dysfunction. Continuum (Minneapolis, Minn.), 21(3 Behavioral Neurology and Neuropsychiatry), 646-659. doi: 10.1212/01.CON.0000466658.05156.54

Rakesh, D., Fernando, K. B., \& Mansour L, S. (2020). Functional dedifferentiation of the brain during healthy aging. Journal of Neurophysiology, 123(4), 1279-1282. doi: 10.1152/jn.00039.2020

Ray, K. L., Ragland, J. D., MacDonald, A. W., Gold, J. M., Silverstein, S. M., Barch, D. M., \& Carter, C. S. (2019). Dynamic reorganization of the frontal parietal network during cognitive control and episodic memory. BioRxiv. doi: 10.1101/709220

Reineberg, A. E., Andrews-Hanna, J. R., Depue, B. E., Friedman, N. P., \& Banich, M. T. (2015). Resting-state networks predict individual differences in common and specific aspects of 
executive function. Neuroimage, 104, 69-78. doi: 10.1016/j.neuroimage.2014.09.045

Reuter-Lorenz, Patricia A., \& Cappell, K. A. (2008). Neurocognitive Aging and the

Compensation Hypothesis. Current Directions in Psychological Science, 17(3), 177-182.

doi: 10.1111/j.1467-8721.2008.00570.x

Reuter-Lorenz, Patricia A., Festini, S. B., \& Jantz, T. K. (2016). Executive functions and neurocognitive aging. In Handbook of the psychology of aging (pp. 245-262). Elsevier. doi: 10.1016/B978-0-12-411469-2.00013-3

Reuter-Lorenz, P A, Stanczak, L., \& Miller, A. C. (1999). Neural recruitment and cognitive aging: two hemispheres are better than one, especially as you age. Psychological Science, 10(6), 494-500. doi: 10.1111/1467-9280.00195

Rieck, J. R., Baracchini, G., \& Grady, C. L. (2021). Contributions of brain function and structure to three different domains of cognitive control in normal aging. Journal of Cognitive Neuroscience, 1-22.doi: 10.1162/jocn_a_01685

Rieck, J. R., Baracchini, G., Nichol, D., Abdi, H., \& Grady, C. L. (2021). Reconfiguration and dedifferentiation of functional networks during cognitive control across the adult lifespan. Neurobiology of Aging, 106, 80-94. doi: 10.1016/j.neurobiolaging.2021.03.019

Romero-Garcia, R., Atienza, M., \& Cantero, J. L. (2014). Predictors of coupling between structural and functional cortical networks in normal aging. Human Brain Mapping, 35(6), 2724-2740. doi: 10.1002/hbm.22362

Rubinov, M., \& Sporns, O. (2010). Complex network measures of brain connectivity: uses and interpretations. Neuroimage, 52(3), 1059-1069. doi: 10.1016/j.neuroimage.2009.10.003

Sadaghiani, S., \& D’Esposito, M. (2015). Functional Characterization of the Cingulo-Opercular Network in the Maintenance of Tonic Alertness. Cerebral Cortex, 25(9), 2763-2773. doi: 


\subsection{3/cercor/bhu072}

Salthouse, T. A., Atkinson, T. M., \& Berish, D. E. (2003). Executive functioning as a potential mediator of age-related cognitive decline in normal adults. Journal of Experimental Psychology: General, 132(4), 566-594. doi: 10.1037/0096-3445.132.4.566

Salthouse, T. A. (2005). Relations between cognitive abilities and measures of executive functioning. Neuropsychology, 19(4), 532-545. doi: 10.1037/0894-4105.19.4.532

Sambataro, F., Murty, V. P., Callicott, J. H., Tan, H.-Y., Das, S., Weinberger, D. R., \& Mattay, V. S. (2010). Age-related alterations in default mode network: impact on working memory performance. Neurobiology of Aging, 31(5), 839-852. doi:

10.1016/j.neurobiolaging.2008.05.022

Schmidt, E. L., Burge, W., Visscher, K. M., \& Ross, L. A. (2016). Cortical thickness in frontoparietal and cingulo-opercular networks predicts executive function performance in older adults. Neuropsychology, 30(3), 322-331. doi: 10.1037/neu0000242

Schretlen, D., Pearlson, G. D., Anthony, J. C., Aylward, E. H., Augustine, A. M., Davis, A., \& Barta, P. (2000). Elucidating the contributions of processing speed, executive ability, and frontal lobe volume to normal age-related differences in fluid intelligence. Journal of the International Neuropsychological Society, 6(1), 52-61. doi: 10.1017/s1355617700611062

Seider, T. R., Porges, E. C., Woods, A. J., \& Cohen, R. A. (2021). Dedifferentiation of Functional Brain Activation Associated With Greater Visual Discrimination Accuracy in Middle-Aged and Older Adults. Frontiers in Aging Neuroscience, 13, 651284. doi:

10.3389/fnagi.2021.651284

Sestieri, C., Corbetta, M., Romani, G. L., \& Shulman, G. L. (2011). Episodic memory retrieval, parietal cortex, and the default mode network: functional and topographic analyses. The 
Journal of Neuroscience, 31(12), 4407-4420. doi: 10.1523/JNEUROSCI.3335-10.2011

Shine, J. M., Bissett, P. G., Bell, P. T., Koyejo, O., Balsters, J. H., Gorgolewski, K. J., ...

Poldrack, R. A. (2016). The Dynamics of Functional Brain Networks: Integrated Network

States during Cognitive Task Performance. Neuron, 92(2), 544-554. doi:

10.1016/j.neuron.2016.09.018

Siegel, J. S., Power, J. D., Dubis, J. W., Vogel, A. C., Church, J. A., Schlaggar, B. L., \& Petersen, S. E. (2014). Statistical improvements in functional magnetic resonance imaging analyses produced by censoring high-motion data points. Human Brain Mapping, 35(5), 1981-1996. doi: $10.1002 / \mathrm{hbm} .22307$

Siman-Tov, T., Bosak, N., Sprecher, E., Paz, R., Eran, A., Aharon-Peretz, J., \& Kahn, I. (2016). Early Age-Related Functional Connectivity Decline in High-Order Cognitive Networks. Frontiers in Aging Neuroscience, 8, 330. doi: 10.3389/fnagi.2016.00330

Sorel, O., \& Pennequin, V. (2008). Aging of the planning process: the role of executive functioning. Brain and Cognition, 66(2), 196-201. doi: 10.1016/j.bandc.2007.07.006

Spaan, P. E. J. (2015). Episodic and semantic memory functioning in very old age: Explanations from executive functioning and processing speed theories. Cogent Psychology, 2(1). doi: $10.1080 / 23311908.2015 .1109782$

Spreng, R. N., \& Schacter, D. L. (2012). Default network modulation and large-scale network interactivity in healthy young and old adults. Cerebral Cortex, 22(11), 2610-2621. doi: 10.1093/cercor/bhr339

Thompson, B. (1991). A Primer on the Logic and Use of Canonical Correlation Analysis. Undefined.

Thomson, G. (1939). The factorial analysis of human ability. British Journal of Educational 
Psychology, 9(2), 188-195. doi: 10.1111/j.2044-8279.1939.tb03204.x

Tomaszewski Farias, S., Cahn-Weiner, D. A., Harvey, D. J., Reed, B. R., Mungas, D., Kramer, J.

H., \& Chui, H. (2009). Longitudinal changes in memory and executive functioning are

associated with longitudinal change in instrumental activities of daily living in older adults.

The Clinical Neuropsychologist, 23(3), 446-461. doi: 10.1080/13854040802360558

van den Heuvel, M. P., \& Hulshoff Pol, H. E. (2010). Exploring the brain network: a review on

resting-state fMRI functional connectivity. European Neuropsychopharmacology, 20(8),

519-534. doi: 10.1016/j.euroneuro.2010.03.008

Varangis, E., Habeck, C. G., Razlighi, Q. R., \& Stern, Y. (2019). The effect of aging on resting

state connectivity of predefined networks in the brain. Frontiers in Aging Neuroscience, 11,

234. doi: 10.3389/fnagi.2019.00234

Voss, M. W., Prakash, R. S., Erickson, K. I., Basak, C., Chaddock, L., Kim, J. S., ... Kramer, A.

F. (2010). Plasticity of brain networks in a randomized intervention trial of exercise training in older adults. Frontiers in Aging Neuroscience, 2. doi: 10.3389/fnagi.2010.00032

Wen, W., Zhu, W., He, Y., Kochan, N. A., Reppermund, S., Slavin, M. J., ... Sachdev, P. (2011).

Discrete neuroanatomical networks are associated with specific cognitive abilities in old age. The Journal of Neuroscience, 31(4), 1204-1212. doi:

10.1523/JNEUROSCI.4085-10.2011

Weschler, D. (2008). WAIS-IV : Wechsler adult intelligence scale (4th ed.). Pearson.

Wig, G. S. (2017). Segregated systems of human brain networks. Trends in Cognitive Sciences, 21(12), 981-996. doi: 10.1016/j.tics.2017.09.006

Woods, S. P., Weinborn, M., Velnoweth, A., Rooney, A., \& Bucks, R. S. (2012). Memory for intentions is uniquely associated with instrumental activities of daily living in healthy older 
adults. Journal of the International Neuropsychological Society, 18(1), 134-138. doi: $10.1017 / \mathrm{S} 1355617711001263$

Yin, S., Deák, G., \& Chen, A. (2018). Coactivation of cognitive control networks during task switching. Neuropsychology, 32(1), 31-39. doi: 10.1037/neu0000406

Zaninotto, P., Batty, G. D., Allerhand, M., \& Deary, I. J. (2018). Cognitive function trajectories and their determinants in older people: 8 years of follow-up in the English Longitudinal Study of Ageing. Journal of Epidemiology and Community Health, 72(8), 685-694. doi: 10.1136/jech-2017-210116

Zhang, H.-Y., Chen, W.-X., Jiao, Y., Xu, Y., Zhang, X.-R., \& Wu, J.-T. (2014). Selective vulnerability related to aging in large-scale resting brain networks. Plos One, 9(10), e108807. doi: 10.1371/journal.pone.0108807

Zlotnik, G., \& Vansintjan, A. (2019). Memory: an extended definition. Frontiers in Psychology, 10, 2523. doi: 10.3389/fpsyg.2019.02523

Zwick, W. R., \& Velicer, W. F. (1986). Comparison of five rules for determining the number of components to retain. Psychological Bulletin, 99(3), 432-442. doi:

$10.1037 / 0033-2909.99 .3 .432$ 